\title{
Changes in Physicochemical Properties and Qualities of Red Brown Rice at Different Storage Temperatures
}

\author{
Tao Wang ${ }^{1}$, Nana She ${ }^{1}$, Mengnan Wang ${ }^{1}$, Bo Zhang ${ }^{1}$, Jiaxing Qin ${ }^{1}$, Jingyuan Dong ${ }^{1}$, Guozhen Fang ${ }^{1, *}$ \\ and Shuo Wang ${ }^{1,2}$ \\ 1 State Key Laboratory of Food Nutrition and Safety, Tianjin University of Science and Technology, \\ Tianjin 300457, China; ahzytaowang@163.com (T.W.); S13652006697@163.com (N.S.); \\ wanmn0000@163.com (M.W.); zhangbo0083@126.com (B.Z.); qinjiaxing1995@163.com (J.Q.); \\ 16622880324@163.com (J.D.); s.wang@tust.edu.cn (S.W.) \\ 2 Tianjin Key Laboratory of Food Science and Health, School of Medicine, Nankai University, \\ Tianjin 300071, China \\ * Correspondence: fangguozhen@tust.edu.cn; Tel.: +86-022-6091-2493
}

Citation: Wang, T.; She, N.; Wang, M.; Zhang, B.; Qin, J.; Dong, J.; Fang, G.; Wang, S. Changes in Physicochemical Properties and Qualities of Red Brown Rice at Different Storage Temperatures. Foods 2021, 10, 2658. https://doi.org/ $10.3390 /$ foods 10112658

Academic Editor: Carla Brites

Received: 29 September 2021

Accepted: 28 October 2021

Published: 2 November 2021

Publisher's Note: MDPI stays neutral with regard to jurisdictional claims in published maps and institutional affiliations.

Copyright: (c) 2021 by the authors. Licensee MDPI, Basel, Switzerland. This article is an open access article distributed under the terms and conditions of the Creative Commons Attribution (CC BY) license (https:// creativecommons.org/licenses/by/ $4.0 /)$.

\begin{abstract}
The effects of storage temperature on the physicochemical properties and qualities of red brown rice were investigated in this study. The samples were vacuum-packed in nylon/polyethylene pouches and stored at $15{ }^{\circ} \mathrm{C}, 25^{\circ} \mathrm{C}$ and $35^{\circ} \mathrm{C}$ for 12 weeks. The moisture content decreased as storage time was prolonged. Rice stored at $15^{\circ} \mathrm{C}$ and $25^{\circ} \mathrm{C}$ had a lower falling range of water content compared to the samples stored at $35^{\circ} \mathrm{C}$. Free fatty acid values increased fastest when samples were stored at a high temperature, and the rise can be effectively delayed at low temperatures. The $\mathrm{pH}$ of residual cooking water and adhesiveness decreased, while the heating water absorption rate and hardness increased during storage for red and brown rice. Low-field nuclear magnetic resonance results indicate that water molecules migrated, the binding force of $\mathrm{H}$ protons became stronger and the bonds between molecules became closer with increased storage duration. Temperature had an obvious correlation with starch granules and protein structure, characterized by a scanning electron microscope and Fourier transform infrared spectroscopy. Low temperatures significantly retarded those changes. The results indicate that storage temperature is a vital factor affecting the physicochemical properties and qualities of red brown rice and provided reference and theoretical basis for the actual storage of red brown rice.
\end{abstract}

Keywords: red brown rice; storage temperature; physicochemical property; quality

\section{Introduction}

Rice (Oryza sativa L.) is a staple food for more than $60 \%$ of the world's population, especially in Asia [1]. As a major dietary source of carbohydrates, rice plays a critical role in meeting energy needs and nutrient intake [2]. At present, with the progress of society and the development of the economy, people's living standards are improving day by day, and awareness of nutrition and health is constantly being enhanced. The concept of food consumption has also undergone a huge change. People's consumption of rice is no longer a simple solution to food and clothing, but a transformation of nutrition, healthcare and food therapy. Colored rice has gradually come into public view due to its rich nutrition and good medicinal effects. Red rice is one of the most widely studied types of colored rice. It is not only rich in nutrients, but also has the functions of activating blood circulation, eliminating stasis and moisturizing skin, and it has anti-aging properties as well as benefits in healthcare, etc. [3]. Since ancient times, it has been considered a good nourishing product and a good homologous substance of medicine and food, which is favored by consumers and has great market potential [4].

Brown rice is the whole fruit of unshelled rice, which is composed of four parts: the cortex, aleurone layer, embryo and endosperm. Brown rice is rich in nutrients and natural 
biological active substances (such as $\gamma$-aminobutyric acid, $\gamma$-glutamyl alcohol, glutathione, ceramide, etc.) that white rice lacks because it retains the germ and rice bran layer. These are confirmed to have anticancer properties and prevention and curing effects for ailments such as of diabetes, high cholesterol and obesity in human health, and disease prevention and the treatment of modern civilization is of great significance [5]. Therefore, brown rice is listed as a whole-grain healthy food by the U.S. Food and Drug Administration (FDA), which advocates eating it straight. Storage is a necessary stage from harvest to rice consumption and should be carefully controlled because a large number of physical, chemical and physiological changes occur during storage, which greatly affect the final quality of rice $[6,7]$. However, due to the loss of the protection given by the rice husk, brown rice embryos and endosperms are exposed and easily damaged by mechanical mechanisms. The increase in enzyme activity led to the acceleration of lipid degradation during storage and the decline of brown rice quality [8-10]. At the same time, brown rice is susceptible to insect mildew, which reduces its edible and economic value.

At present, the research on red rice mainly focuses on red rice's epidermal pigment [11], biological activity [12], red rice products and other effects. The planting areas and yield of red rice are increasing continuously. However, there have been no literature reports on suitable storage conditions for red rice. Hence, it is vital to select the suitable packaging materials and packaging methods for storing red brown rice. However, the traditional plastic woven bags and other packaging materials are not adequate barriers or moistureproof, thus increasing the possibility of red brown rice mildew during storage. Generally, rice qualities were mainly evaluated by the changes of starch gelatinization and texture [13]. Meanwhile, the changes of water content, microstructure and protein secondary structure can directly reflect the quality of rice $[14,15]$. In this study, red brown rice was vacuumpacked in nylon/polyethylene little pouches, which can adequately protect the red brown rice from the outside environment and ensure the quality of red brown rice. Therefore, the change in physical and chemical indices and the quality of red brown rice under the condition of vacuum packaging was studied in this paper. It aims to provide technical reference and theoretical basis for the actual storage of red brown rice and the findings can be popularized and applied to the storage of colored rice, effectively solving the problem of grain storage, achieving safe grain storage and providing an effective storage method both for farmers who plant colored rice and for consumers, so as to delay the deterioration of its quality and reduce losses.

\section{Materials and Methods}

\subsection{Chemicals and Reagents}

The red brown rice was purchased from Jinggangshan in the Jiangxi province and harvested in October 2019. The vacuum bags were purchased from Tmall stores and were made of nylon/polyethylene composite. The specifications and the water vapor transmission were $12 \times 20 \mathrm{~cm}$ and $0.5 \mathrm{~g} /\left(\mathrm{m}^{2} / 24 \mathrm{~h}\right)$, respectively. N-hexane was purchased from Aladdin Biochemical Technology Co., LTD (Shanghai, China). Other chemicals were purchased by Sinopharm Chemical Reagent Co., LTD (Tianjin, China). N-hexane was of chromatographic grade. The grade of the other regents and chemicals was analytical and used with no additional purification.

\subsection{Red Brown Rice Storage}

Temperature and humidity were the most vital environmental factors influencing rice quality during storage. Typically, high-humidity storage conditions would easily cause rice mildew [16,17]. To satisfy consumer demand, harvested red brown rice must be stored for extended periods under conditions that maintain its quality. In this strategy, red brown rice was repacked into vacuum bags weighing $200 \mathrm{~g}$ each and placed in an artificial climate box for simulated storage. A low room-temperature and high temperature were set at $\left(15,25\right.$ and $\left.35{ }^{\circ} \mathrm{C}\right)$, respectively, for each sample, and the humidity was set at $65 \%$. The 
storage period was 12 weeks. Samples were taken every 2 weeks and a series of indices were measured.

\subsection{Determination of Moisture Content and Fatty Acid Value of Red Brown Rice}

Moisture content was determined by drying the red brown rice flour to a constant weight at $105{ }^{\circ} \mathrm{C}$ (American Association of Cereal Chemists, 2000), and fatty acid value was determined using the official standard method (American Association of Cereal Chemists, 1976).

\subsection{LF-NMR Experiments}

The red brown rice sample was weighed at about $3 \mathrm{~g}$, then wrapped in plastic wrap and put into a $25 \mathrm{~mm}$ diameter sample tube. The height of the sample in the tube should not exceed $2 \mathrm{~cm}$. The reference material of soybean oil was used to calibrate the instruments. A nuclear magnetic resonance analyzer (MicroMR-025, Newmai Electronic Technology Co., LTD, Suzhou, China) was used to acquire the transverse relaxation time $\left(\mathrm{T}_{2}\right)$ of the sample. The waiting time (TW), the echo time (TE) and the number of echoes (NECH) were $1500 \mathrm{~ms}, 0.1 \mathrm{~ms}$ and 4000, respectively.

\subsection{Determination of Cooking Characteristics of Red Brown Rice}

\subsubsection{Determination of Heating Water Absorption Rate of Red Brown Rice}

A total of $10 \mathrm{~g}\left(w_{0}\right)$ of red brown rice was accurately weighed and placed in an aluminum box. Distilled water that was twice the weight of the red brown rice was added, and the rice was soaked for $0.5 \mathrm{~h}$. We removed and drained the remaining water on the surface of the rice grains with filter paper, then added distilled water that was 1.4 times the weight of the red brown rice, covered the aluminum box and put it on the steamer of a boiled pot, heated it for $30 \mathrm{~min}$, kept it warm for $15 \mathrm{~min}$, took it out and weighed the rice $\left(w_{1}\right)$.

$$
\text { heating water absorption rate }(\%)=\frac{w_{1}-w_{0}}{w_{0}} \times 100
$$

\subsubsection{Determination of $\mathrm{pH}$ Value of Red Brown Rice Leach}

We weighed the $3 \mathrm{~g}$ of red brown rice cooked in Section 2.5.1 and put it into a colorimetric test tube of $25 \mathrm{~mL}$, added water to a volume $12.5 \mathrm{~mL}$, oscillated it in a water bath at $40{ }^{\circ} \mathrm{C}$ for $1 \mathrm{~h}$, then added $25 \mathrm{~mL}$ distilled water at a constant volume, shook it well and centrifuged it at $3000 \mathrm{r} / \mathrm{min}$ for $10 \mathrm{~min}$. After centrifugation, $5 \mathrm{~mL}$ of supernatant was sucked out and put into a $5 \mathrm{~mL}$ beaker. The $\mathrm{pH}$ value of the red rice leach was measured with a $\mathrm{pH}$ meter.

\subsection{The Texture Properties of Cooked Red Brown Rice}

A texture analyzer (Stable micro systems Co., Godalming, UK) which was loaded with $10 \mathrm{~g}$ of trigger force was used to measure the texture characteristics of cooked red brown rice. The probe of the texture analyzer was an aluminum cylindrical probe $(\mathrm{P} / 36 \mathrm{R})$. The pre-test speed, test speed and post-test speed were $4.0 \mathrm{~mm} / \mathrm{s}, 1.0 \mathrm{~mm} / \mathrm{s}$ and $1.0 \mathrm{~mm} / \mathrm{s}$, respectively. The degree of deformation was set to $30 \%$ of the sample height. Four full grains of red rice were selected from the cooked rice and placed on the platform of the texture apparatus. The experiment was repeated at least three times in parallel, and the average value was taken to analyze the results.

\subsection{Scanning Electron Microscopy}

Scanning electron microscopy (SEM) was used to observe the changes in the crosssection microstructure of red brown rice during storage. Red brown rice with a relatively smooth cross section and natural fractures during each storage period was selected as the sample to be tested. The sample was fixed on the vertical sample paste board with 
conductive adhesive, and the cross section of the rice sample was taken upward. Finally, the sample was characterized by a scanning electron microscope at a magnification of $1000 \times$.

\subsection{Determination of Secondary Structure of Proteins}

The relative content of protein secondary structures was obtained by a Fourier transform infrared spectrometer (IS50, Thermo Nicolet Co., LLC, Waltham, MA, USA). Red brown rice was milled and sifted through 120 mesh. An accurately weighted sample of $1.0 \mathrm{mg}$ was added into a mortar containing $150 \mathrm{mg} \mathrm{KBr}$. Then, the mixture was grinded into pellets for analysis. The spectrograms were collected with a wave number range of $4000-400 \mathrm{~cm}^{-1}$ [18]. The spectra in the region of $1700-1600 \mathrm{~cm}^{-1}$ were deconvolved by OMINC 8 (Thermo, Waltham, MA, USA).

\section{Results and Discussion}

\subsection{Moisture Content}

Moisture content is one of the most important indicators in measuring the freshness and quality of red rice. It can not only determine whether red rice can be stored safely, but also affects the retention of the aroma of red rice, and it is closely related to the final edible quality [19]. An appropriate water level can closely combine with starch, protein and other hydrophilic colloids so as to improve the edible quality. Rice with a high moisture content can induce the survival and growth of pests and microorganisms. Mold and microorganisms generally increase in proportion with the moisture content [20]. Too low a moisture content will cause the grain to break and reduce its viscosity after cooking, which will affect its taste and edible quality. As shown in Figure 1a, the moisture content of red brown rice stored at $15^{\circ} \mathrm{C}$ and $25^{\circ} \mathrm{C}$ did not change significantly in the first 8 weeks, and even showed a slight increase. The main reason for the increase in moisture content was due to the moisture exchange between the rice and its surroundings. It showed a gradually decreasing trend from the eighth week. After 12 weeks, the moisture contents decreased to $12.04 \%$ and $11.67 \%$, respectively. The moisture content showed a continuously decreasing trend, and finally decreased to $9.57 \%$ when stored at $35^{\circ} \mathrm{C}$ for 12 weeks. High temperatures can enhance the enzyme activities and respiratory metabolism in the grains of red brown rice, enhance the water exchange between the outside and the brown rice, accelerate the rate of water loss, and thus accelerate the deterioration of the quality of brown rice. Therefore, it is significant and necessary to monitor the changes in the water content of red brown rice at different storage temperatures during the storage period.

$\mathbf{a}$

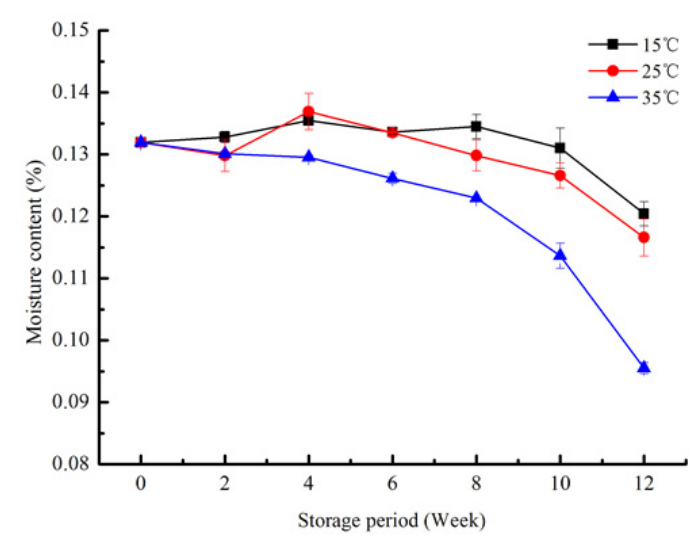

b

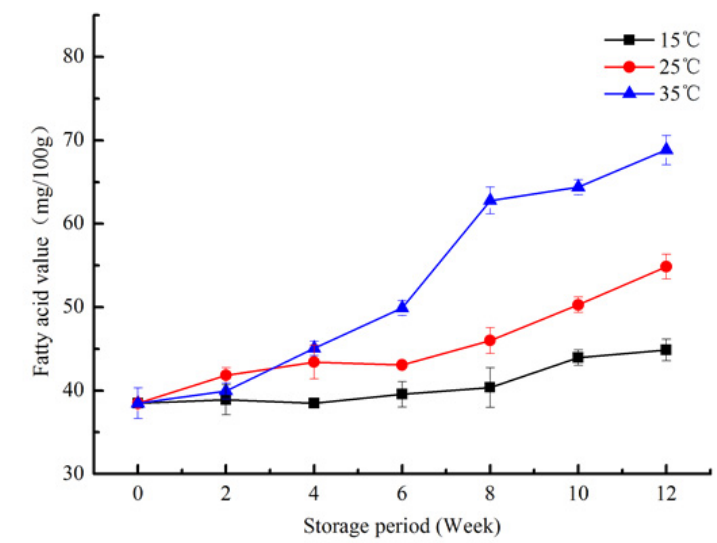

Figure 1. Changes in physicochemical indices of red brown rice under different storage temperature ((a): moisture content; (b): fatty acid values). 


\subsection{Fatty Acid Value}

The changes in the free fatty acid values of the red brown rice with storage time are shown in Figure 1b. During storage, the fatty acid values increased gradually, and it is obvious that the fatty acid values of the red brown rice stored at a high temperature $\left(35^{\circ} \mathrm{C}\right)$ were higher than those of rice stored at lower temperatures $\left(15^{\circ} \mathrm{C}\right.$ and $\left.25^{\circ} \mathrm{C}\right)$ (Figure $1 \mathrm{~b}$ ). Although a gradual increase in fatty acid values (from $38.48 \mathrm{mg} / 100 \mathrm{~g}$ to $44.86 \mathrm{mg} / 100 \mathrm{~g}$ ) was observed in red brown rice stored at $15^{\circ} \mathrm{C}$, much higher values were obtained in red brown rice stored at $25^{\circ} \mathrm{C}(54.86 \mathrm{mg} / 100 \mathrm{~g})$ and $35^{\circ} \mathrm{C}(68.83 \mathrm{mg} / 100 \mathrm{~g})$ after 12 weeks of storage. Lipid content is one of the most important components of rice. The deterioration degree of rice quality during storage can be reflected by the change in fatty acid value, which is one of the important indices to measure the freshness and aging degree of rice. Too much accumulation of fatty acids during storage will lead to rice rancidity and seriously degrade its edible quality [21]. The influence of temperature on fatty acid value is mainly due to the influence of temperature on enzyme activity. Within a certain range, the higher the temperature, the stronger the enzyme activity, which leads to a faster rate of fat decomposition and a faster increase in fatty acid value.

\subsection{The LF-NMR Experiments}

Low-field nuclear magnetic resonance (LF-NMR) has become an alternative and effective method to quantify the changes in water status and visualize the internal water distribution of food $[22,23]$. In order to further study the moisture distribution and moisture relaxation behavior of red brown rice during storage, this study used the Carr-PurcellMeiboom-Gill(CPMG) pulse sequencing to measure the transverse relaxation time $\left(\mathrm{T}_{2}\right)$. The value of $T_{2}$ can reflect the motion of $H$ protons, and different values of $T_{2}$ represent different degrees of freedom of the water [24]. The $T_{2}$ inversion map is used to distinguish the moisture with different fluidity in the form of peaks. Different peaks represent different fluidity of water molecules. When the binding force of water molecules is weak, the corresponding $\mathrm{T}_{2}$ value is large, and the peak in the inversion map is to the right $[25,26]$. From Figure $2 \mathrm{a}$, we can see two peaks, indicating that there are two kinds of water molecules with different fluidity in the fresh red brown rice. The peak range of the first peak is $0.1-10 \mathrm{~ms}$, and the peak area proportion is more than $85 \%$, which is called a $\mathrm{T}_{21}$ peak. The peak range of the second peak is $10-1000 \mathrm{~ms}$, which is called a $\mathrm{T}_{22}$ peak. The $\mathrm{T}_{21}$ and $\mathrm{T}_{22}$ peaks represent bound and free water in red brown rice, respectively. The area of peak $\mathrm{T}_{21}$ is significantly larger than that of peak $\mathrm{T}_{22}$; that is, the bound water content is significantly higher than the free water content. This is because the free water is mainly lost by the drying of brown rice before storage, and the bound water is not easy to lose due to the close combination. As can be seen from Figure $2 b, c$, with the extension of storage time, the peak areas of $T_{21}$ and $T_{22}$ both show a decreasing trend, indicating that water content gradually decreases in the storage process, and the decreasing rate is related to temperature. The higher the temperature, the higher the rate of decline, which was in accord with the above conclusion of moisture content determination. The peak area of $\mathrm{T}_{21}$ decreased from 2571.78 to 2479.74 when stored at $15^{\circ} \mathrm{C}$. At $25^{\circ} \mathrm{C}$ and $35^{\circ} \mathrm{C}$, the peak area decreased to 2444.37 and 2320.28, respectively. A high temperature will accelerate the vibration frequency of the $\mathrm{H}$ proton, which will lead to the easy loss of water. Moreover, red rice will be heated and cause pests, which will increase the amount of broken rice and deteriorate its quality. Therefore, the storage temperature should be strictly controlled in the storage process.

As can be seen from Table 1, with the extension of storage time, the peak point time of $T_{21}$ and $T_{22}$ decreased. In other words, the peak shifted to the left, and the degree of shift varied with the temperature. This indicated that during the storage process, water molecules migrated, the binding force of $\mathrm{H}$ protons became stronger and stronger, and the bonds between molecules became closer. 

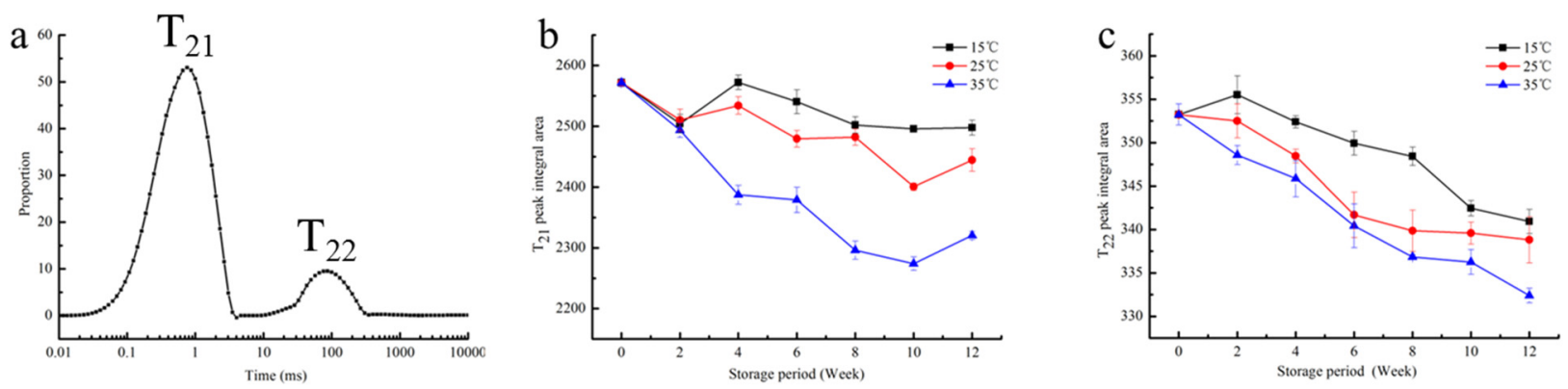

Figure 2. Distribution of $T_{2}$ relaxation time of fresh red brown rice (a) and changes in $T_{21}(\mathbf{b})$ and $T_{22}(\mathbf{c})$ peak area in red brown rice at different temperatures.

Table 1. Changes in $\mathrm{T}_{2}$ peak time of red brown rice at different temperatures.

\begin{tabular}{|c|c|c|c|c|c|c|}
\hline \multirow{2}{*}{ Storage Time (Week) } & \multicolumn{3}{|c|}{$\mathrm{T}_{21}(\mathrm{~ms})$} & \multicolumn{3}{|c|}{$\mathrm{T}_{22}(\mathrm{~ms})$} \\
\hline & $15^{\circ} \mathrm{C}$ & $25^{\circ} \mathrm{C}$ & $35^{\circ} \mathrm{C}$ & $15^{\circ} \mathrm{C}$ & $25{ }^{\circ} \mathrm{C}$ & $35^{\circ} \mathrm{C}$ \\
\hline 0 & 0.76 & 0.76 & 0.76 & 84.26 & 84.26 & 84.26 \\
\hline 2 & 0.76 & 0.66 & 0.76 & 79.42 & 72.36 & 70.69 \\
\hline 4 & 0.76 & 0.66 & 0.66 & 76.14 & 69.08 & 69.08 \\
\hline 6 & 0.66 & 0.66 & 0.63 & 66.94 & 65.73 & 69.08 \\
\hline 8 & 0.66 & 0.66 & 0.57 & 66.22 & 63.37 & 60.88 \\
\hline 10 & 0.66 & 0.66 & 0.57 & 60.08 & 62.94 & 57.22 \\
\hline 12 & 0.66 & 0.63 & 0.50 & 60.08 & 57.86 & 49.73 \\
\hline
\end{tabular}

\subsection{Microstructure Characterization}

The cross-sectional microstructure of fresh red brown rice and red brown rice stored at different temperatures for 12 weeks are shown in Figure 3. Figure 3a shows that the cross section of fresh red brown rice was not completely smooth. Protein, lipid and starch granules were closely linked together. Protein was embedded in starch granules, and these mostly existed in the form of complex granules, with only a few single starch granules. However, regardless of the complex or single granules, the edges and corners of starch granules were clearly visible and showed polyhedral crystal structures that were arranged closely and in an orderly fashion. The boundaries between starch granules were clear and distinct. According to Figure $3 \mathrm{~b}-\mathrm{d}$, the cross section of brown rice stored at $15{ }^{\circ} \mathrm{C}$ and $25^{\circ} \mathrm{C}$ did not change significantly. It still existed in the form of complex granules and was arranged neatly, which was close to the initial state as a whole. However, when stored at $35^{\circ} \mathrm{C}$, a few cracks and small holes appeared in the cross section, and some starch granules became blurred. At the same time, the number of single granules increased. The crack may be caused by the decomposition of starch by the debranching enzyme. During the storage process, different degrees of water loss occurred in the rice grains, resulting in the accumulation of starch particles and an increase in density. Eventually, gaps appeared around the granules and the edges of the granules became blurred.

\subsection{FTIR Analysis}

In the infrared spectrum analysis, the peaks at $1700-1600 \mathrm{~cm}^{-1}$ represent the amide I band of protein. It is known as being the most valuable for studying the secondary structure of proteins because it includes four different kinds of secondary structures: $\alpha$-helices, $\beta$-sheets, $\beta$-turns and randomly coiled structures, which are connected by the $\mathrm{C} \bullet \mathrm{O}$ stretching of peptide bonds under various environment $[27,28]$.

The changes in protein secondary structure during the storage of red brown rice under different storage conditions were observed more accurately by FTIR, and the FTIR data were analyzed by Peak Fit 4.12. The results are shown in Table 2. From the table, it can be seen that the proportion of $\beta$-turn in fresh red brown rice was the highest, followed by $\beta$-sheet, and finally by $\alpha$-helix and random coil, indicating that $\beta$-turn was the main 
protein secondary structure in red rice. In the storage process, with the increase in time, the relative content of the $\alpha$-helix decreased gradually, random coil increased gradually, and the relative content of $\beta$-turn and $\beta$-sheet fluctuated without specific laws and trends but still occupied large proportions, which were the main existing forms. The stability of the $\alpha$-helix structure is closely related to non-covalent bonds, such as hydrogen bonds, which can be influenced by temperature, $\mathrm{pH}$ and other factors. The decrease in $\alpha$-helix structure content was caused by hydrogen bond fracturing. The increase in random coil content indicated that brown rice protein developed from an ordered state to disordered state during storage, and its stability decreased.
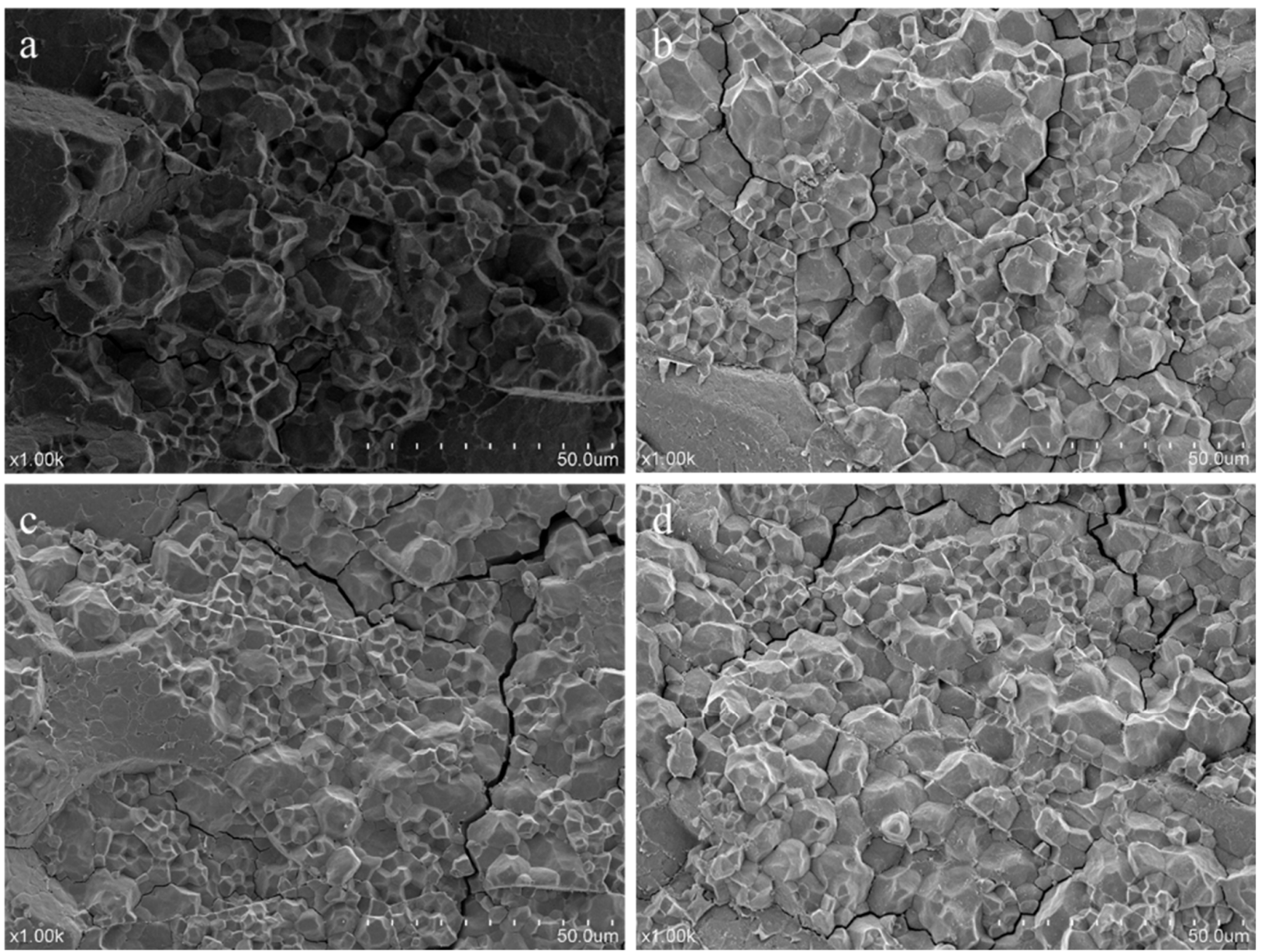

Figure 3. Effect of temperature on the cross-sectional microstructure of red brown rice $\left((\mathbf{a})\right.$ : fresh rice, $(\mathbf{b})$ : stored at $15{ }^{\circ} \mathrm{C}$, (c): stored at $25^{\circ} \mathrm{C},(\mathrm{d})$ : stored at $\left.35^{\circ} \mathrm{C}\right)$.

Table 2. The effect of temperature on the secondary structure of red brown rice protein.

\begin{tabular}{|c|c|c|c|c|c|}
\hline Storage Temperature & Storage Time (Week) & $\alpha$-Helix & $\beta$-Sheet & $\beta$-Turn & Random Coil \\
\hline & 0 & 0.14 & 0.30 & 0.41 & 0.15 \\
\hline \multirow{3}{*}{$15^{\circ} \mathrm{C}$} & 4 & 0.10 & 0.28 & 0.46 & 0.16 \\
\hline & 8 & 0.13 & 0.27 & 0.45 & 0.15 \\
\hline & 12 & 0.11 & 0.33 & 0.35 & 0.21 \\
\hline \multirow{3}{*}{$25^{\circ} \mathrm{C}$} & 4 & 0.13 & 0.28 & 0.40 & 0.19 \\
\hline & 8 & 0.12 & 0.31 & 0.42 & 0.15 \\
\hline & 12 & 0.09 & 0.34 & 0.39 & 0.18 \\
\hline \multirow{3}{*}{$35^{\circ} \mathrm{C}$} & 4 & 0.13 & 0.29 & 0.40 & 0.18 \\
\hline & 8 & 0.10 & 0.25 & 0.42 & 0.21 \\
\hline & 12 & 0.08 & 0.32 & 0.40 & 0.20 \\
\hline
\end{tabular}




\subsection{Determination of Cooking and Texture Characteristics}

To investigate the impacts of storage temperature on the cooking characteristics of red brown rice, the heating water absorption rate and $\mathrm{pH}$ of residual cooking water were evaluated. Figure $4 \mathrm{a}, \mathrm{b}$ shows that during the storage of red brown rice, the heating water absorption rate increased, and the $\mathrm{pH}$ of residual cooking water decreased over the storage time. Additionally, temperature had a noteworthy effect on cooking characteristics. The higher the temperature was, the higher the rate of change. High temperatures will accelerate the aging rate. Due to the hardening of the cell walls during the aging process of rice, more water was needed to maintain the polygonal crystal shape during the starch gelatinization process, so the water absorption increased gradually with the extension of storage time. During storage, lipase or microorganisms decomposed non-starch lipids to produce a large number of free fatty acids that accumulated in the rice grains, and the decomposition speed was accelerated under high-temperature conditions. In the process of cooking, acid was dissolved in water, which increased the acidity of the residual cooking water and decreased the $\mathrm{pH}$ value.

a

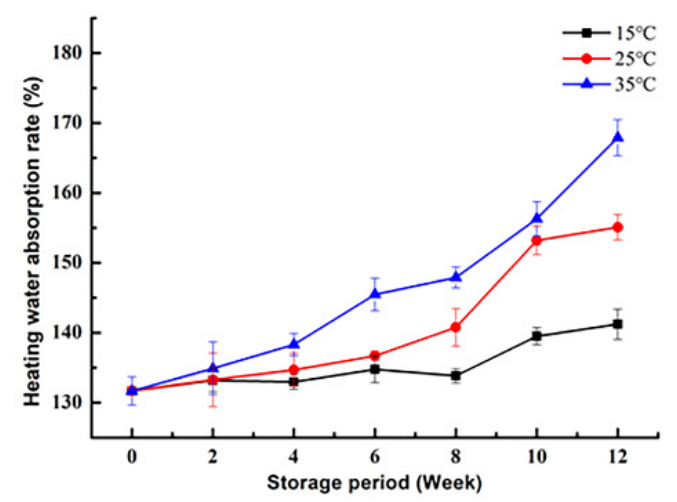

C

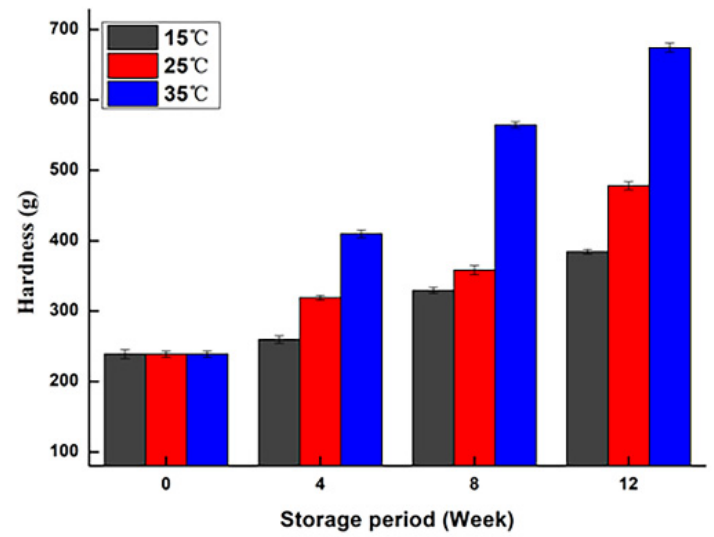

b

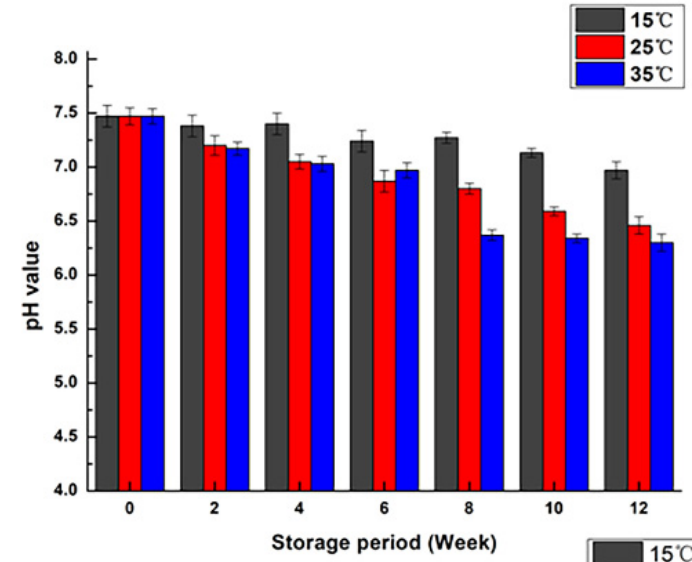

d

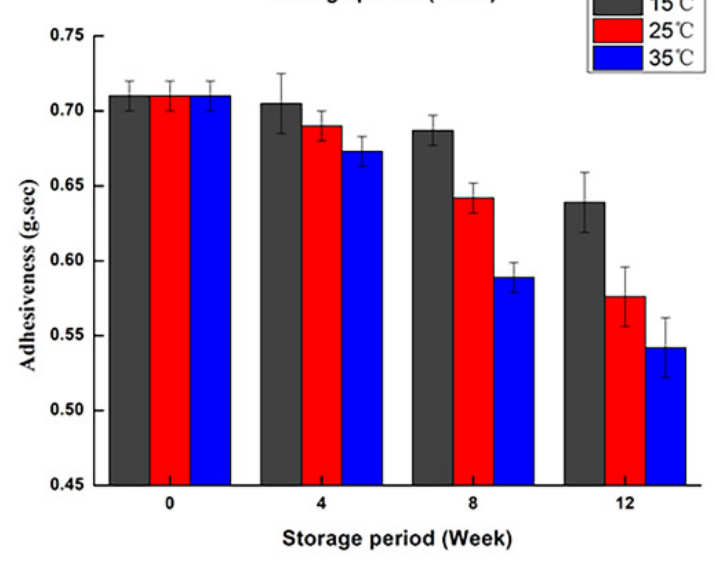

Figure 4. Effect of temperature on cooking and texture characteristics of red brown rice ((a): heating water absorption rate, (b): $\mathrm{pH}$ value, (c): hardness, (d): adhesiveness).

Hardness and adhesiveness served as important indices for evaluating the texture of the cooked rice [29]. The influence of temperature and storage duration on the hardness and adhesiveness are shown in Figure $4 \mathrm{c}, \mathrm{d}$. Data confirmed that the hardness of red brown rice increased and its adhesiveness decreased after storage, which was consistent with the conclusion drawn by Zhou [30]. Compared with low and room temperature storage, the change rate of texture properties under high temperature conditions was the fastest and most obvious. In the storage process, amylopectin was decomposed, the crystal structure of starch became more compact, and starch granule strength increased, which might be the reason for the increase in the hardness of cooked rice after storage [31]. In addition, the leaching of soluble starch was inhibited by the formation of complex fatty 
acids with amylose and protein or the polymerization of amylose molecules themselves, which reduced the rice adhesiveness after long-term storage [32]. Low temperatures can effectively delay the deterioration of red brown rice.

\section{Conclusions}

Changes in the physicochemical characteristic of red brown rice, such as moisture content and distribution, fatty acid value, microstructure and cooking and texture characteristics, apparently occurred during storage under different temperatures. Storage temperature was an important factor affecting the ageing process. With the prolongation of storage time, red brown rice experienced different degrees of aging, which was accelerated at high temperatures and effectively delayed at low temperatures. The selection of appropriate storage conditions can maximize the quality of red brown rice and reduce the waste caused by improper storage. Storage at low temperatures or short-term storage at room temperature is advised to maintain the quality of red brown rice. The present study is helpful in providing farmers and consumers with a storage basis for red rice, so as to maintain grain quality and reduce resource waste caused by improper storage.

Author Contributions: T.W., data curation, methodology, writing-review and editing; N.S., investigation, writing — original draft; M.W., writing — review and editing; B.Z., modifying the manuscript; J.Q., writing—review and editing; J.D., writing—review and editing; G.F., project administration, supervision; S.W., project administration, supervision. All authors have read and agreed to the published version of the manuscript.

Funding: This work was supported by the National Key Research and Development Program of China (project No. 2017YFC1600803).

Institutional Review Board Statement: Not applicable.

Informed Consent Statement: Not applicable.

Data Availability Statement: Not applicable.

Conflicts of Interest: The authors declare no conflict of interest.

\section{References}

1. Kim, M.R.; Wei, C.; Kwon, O.Y.; Liu, X.-W.; Kim, H.C.; Yoon, W.K.; Kim, H.M. Protein Profiles of Major Korean Rice Cultivars. Prev. Nutr. Food Sci. 2007, 12, 103-110.

2. Yang, C.Z.; Shu, X.L.; Zhang, L.L.; Wang, X.Y.; Zhao, H.J.; Ma, C.X.; Wu, D.X. Starch properties of mutant rice high in resistant starch. J. Agric. Food Chem. 2006, 54, 523-528. [CrossRef]

3. Tananuwong, K.; Tangsrianugul, N. Effects of storage conditions and cooking on colour and antioxidant activities of organic pigmented rice. Int. J. Food Sci. Technol. 2013, 48, 67-73. [CrossRef]

4. Pereira, J.A.; Bassinello, P.Z;; Cutrim, V.d.A.; Ribeiro, V.Q. Comparison among Agronomic, Cooking and Nutritional Characteristcs in White and Red Rice Varieties. Rev. Caatinga 2009, 22, 243-248.

5. Bergonio, K.B.; Lucatin, L.G.G.; Corpuz, G.A.; Ramos, N.C.; Duldulao, J.B.A. Improved Shelf Life of Brown Rice by Heat and Microwave Treatment. J. Microbiol. Biotechnol. Food Sci. 2016, 5, 378-385. [CrossRef]

6. Noomhorm, A.; Kongseree, N.; Apintanapong, M. Effect of aging on the quality of glutinous rice crackers. Cereal Chem. 1997, 74, 12-15. [CrossRef]

7. Sodhi, N.S.; Singh, N.; Arora, M.; Singh, J. Changes in physico-chemical, thermal, cooking and textural properties of rice during aging. J. Food Process. Preserv. 2003, 27, 387-400. [CrossRef]

8. Mohapatra, D.; Kumar, S.; Kotwaliwale, N.; Singh, K.K. Critical factors responsible for fungi growth in stored food grains and non-Chemical approaches for their control. Ind. Crop. Prod. 2017, 108, 162-182. [CrossRef]

9. Neme, K.; Mohammed, A. Mycotoxin occurrence in grains and the role of postharvest management as a mitigation strategies. A review. Food Control 2017, 78, 412-425. [CrossRef]

10. Mutungi, C.; Muthoni, F.; Bekunda, M.; Gaspar, A.; Kabula, E.; Abass, A. Physical quality of maize grain harvested and stored by smallholder farmers in the Northern highlands of Tanzania: Effects of harvesting and pre-storage handling practices in two marginally contrasting agro-locations. J. Stored Prod. Res. 2019, 84, 101517. [CrossRef]

11. Xie, H.; Yin, M.; Liu, J.; Cao, Y. Optimization of ultrasonic-assisted extraction of pigment from red rice by response surface methodology. Sci. Technol. Food Ind. 2014, 35, 271-274, 287.

12. Ghasemzadeh, A.; Karbalaii, M.T.; Jaafar, H.Z.E.; Rahmat, A. Phytochemical constituents, antioxidant activity, and antiproliferative properties of black, red, and brown rice bran. Chem. Cent. J. 2018, 12, 17. [CrossRef] 
13. Zhu, L.; Zhang, H.; Wu, G.; Qi, X.; Wang, L.; Qian, H. Effect of structure evolution of starch in rice on the textural formation of cooked rice. Food Chem. 2021, 342, 128205. [CrossRef]

14. Liu, J.; Liu, Y.; Wang, A.; Dai, Z.; Wang, R.; Sun, H.; Strappe, P.; Zhou, Z. Characteristics of moisture migration and volatile compounds of rice stored under various storage conditions. J. Cereal Sci. 2021, 102, 103323. [CrossRef]

15. Zhao, Q.; Lin, J.; Wang, C.; Yousaf, L.; Xue, Y.; Shen, Q. Protein structural properties and proteomic analysis of rice during storage at different temperatures. Food Chem. 2021, 361, 130028. [CrossRef]

16. Chen, Y.; Jiang, W.; Jiang, Z.; Chen, X.; Cao, J.; Dong, W.; Dai, B. Changes in Physicochemical, Structural, and Sensory Properties of Irradiated Brown Japonica Rice during Storage. J. Agric. Food Chem. 2015, 63, 4361-4369. [CrossRef]

17. Yuan, B.; Zhao, C.; Yan, M.; Huang, D.; McClements, D.J.; Huang, Z.; Cao, C. Influence of gene regulation on rice quality: Impact of storage temperature and humidity on flavor profile. Food Chem. 2019, 283, 141-147. [CrossRef]

18. Zhang, L.; Pan, Z.; Shen, K.; Cai, X.; Zheng, B.; Miao, S. Influence of ultrasound-assisted alkali treatment on the structural properties and functionalities of rice protein. J. Cereal Sci. 2018, 79, 204-209. [CrossRef]

19. Ziegler, V.; Paraginski, R.T.; Ferreira, C.D. Grain storage systems and effects of moisture, temperature and time on grain quality-A review. J. Stored Prod. Res. 2021, 91, 101770. [CrossRef]

20. Abdullah, N.; Nawawi, A.; Othman, I. Fungal spoilage of starch-based foods in relation to its water activity (a(w)). J. Stored Prod. Res. 2000, 36, 47-54. [CrossRef]

21. Genkawa, T.; Uchino, T.; Inoue, A.; Tanaka, F.; Hamanaka, D. Development of a low-moisture-content storage system for brown rice: Storability at decreased moisture contents. Biosyst. Eng. 2008, 99, 515-522. [CrossRef]

22. Cheng, S.; Li, R.; Yang, H.; Wang, S.; Lin, R.; Tan, M. Characterisation of moisture migration of shiitake mushroom (Lentinula edodes) during storage and its relationship to quality deterioration. Int. J. Food Sci. Technol. 2020, 55, 2132-2140. [CrossRef]

23. Yang, H.; Cheng, S.; Lin, R.; Wang, S.; Wang, H.; Wang, H.; Tan, M. Investigation on moisture migration, microstructure and quality changes of fresh-cut apple during storage. Int. J. Food Sci. Technol. 2021, 56, 293-301. [CrossRef]

24. Pitombo, R.N.M.; Lima, G. Nuclear magnetic resonance and water activity in measuring the water mobility in Pintado (Pseudoplatystoma corruscans) fish. J. Food Eng. 2003, 58, 59-66. [CrossRef]

25. Fan, D.; Ma, S.; Wang, L.; Zhao, H.; Zhao, J.; Zhang, H.; Chen, W. H-1 NMR studies of starch-water interactions during microwave heating. Carbohydr. Polym. 2013, 97, 406-412. [CrossRef]

26. Kirtil, E.; Oztop, M.H. H-1 Nuclear Magnetic Resonance Relaxometry and Magnetic Resonance Imaging and Applications in Food Science and Processing. Food Eng. Rev. 2016, 8, 1-22. [CrossRef]

27. Ahmed, J.; Ramaswamy, H.S.; Ayad, A.; All, I.; Alvarez, P. Effect of high-pressure treatment on rheological, thermal and structural changes in Basmati rice flour slurry. J. Cereal Sci. 2007, 46, 148-156. [CrossRef]

28. Schwinte, P.; Voegel, J.C.; Picart, C.; Haikel, Y.; Schaaf, P.; Szalontai, B. Stabilizing effects of various polyelectrolyte multilayer films on the structure of adsorbed/embedded fibrinogen molecules: An ATR-FTIR study. J. Phys. Chem. B 2001, 105, 11906-11916. [CrossRef]

29. Zhou, Z.; Robards, K.; Helliwell, S.; Blanchard, C. Effect of storage temperature on cooking behaviour of rice. Food Chem. 2007, 105, 491-497. [CrossRef]

30. Zhou, Z.K.; Robards, K.; Helliwell, S.; Blanchard, C. Composition and functional properties of rice. Int. J. Food Sci. Technol. 2002, 37, 849-868. [CrossRef]

31. Park, C.-E.; Kim, Y.-S.; Park, K.-J.; Kim, B.-K. Changes in, physicochemical characteristics of rice during storage at different temperatures. J. Stored Prod. Res. 2012, 48, 25-29. [CrossRef]

32. Ding, C.; Khir, R.; Pan, Z.; Wood, D.F.; Venkitasamy, C.; Tu, K.; El-Mashad, H.; Berrios, J. Influence of infrared drying on storage characteristics of brown rice. Food Chem. 2018, 264, 149-156. [CrossRef] [PubMed] 